\title{
OS PSEUDOTEXTOS DE P.H.: ESTUDO DE UM CASO-PROBLEMA
}

\author{
Reny Maria Gregolin-Guindaste* \\ Maria Alice Maschio de Godoy**
}

\section{Introdução}

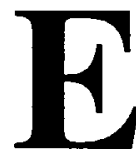

ste trabalho ${ }^{1}$ tem por objetivo a análise lingüística da produção escrita de P.H. ${ }^{2}$ - um menino de 12 anos, aluno de 4." série do primeiro grau, reprovado duas vezes nessa série, com dificuldade em compreensão de ordens, lentidão na execução de tarefas, respostas dissociadas e incoerentes. Apresenta grande facilidade para decorar números, porém dificuldade para resolver operações matemáticas. Seu desempenho em geografia é muito bom, gosta de guias rodoviários e telefônicos. Constitui um caso-problema de alfabetização, pois, apesar de seu bom desempenho no aspecto convencional da escrita, tem grande dificuldade para tecer o texto, tendo sido constatadas dificuldades na compreensão de relativas, o que demonstra dificuldades com subordinações, apesar da facilidade de justapor sentenças coordenadas.

* Universidade Federal do Paraná

** Mestranda da Universidade Federal do Paraná e professora do CEFET-PR, unidade de Medianeira.

1 Este trabalho desenvolveu-se a partir das discussões na disciplina Princípios Lingüísticos da Alfabetização durante o primeiro semestre de 1997, ministrada por Reny Maria GregolinGuindaste, no curso de Mestrado em Letras, área de concentração Lingüística.

2 P. H. está sendo acompanhado no projeto de extensão "Diagnóstico e acompanhamento longitudinal de casos-problemas de alfabetização" por equipe multidisciplinar composta por neuropediatra, psicólogo e lingüista dos departamentos de Pediatria e Lingüística da UFPR. 
Analisaremos três produções escritas de P.H., e o nosso objetivo principal será o mapeamento das suas dificuldades mais acentuadas que, nos textos em questão, apresentam-se como problemas na estrutura da narrativa, falta de zoesão e de unidade temática. Dessa forma, não nos deteremos em questões Jertinentes à convenção da escrita, pois, dada a sua facilidade para memorizar, a aquisição de convenções ortográficas garantiu a P.H. as promoções escolares

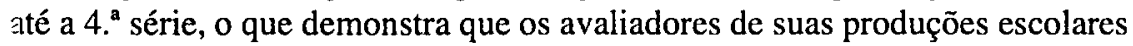
ગriorizaram aspectos mecanicistas e gráficos da escrita e não consideraram elevantes nem o todo significativo da linguagem na dimensão discursiva do iexto, nem a capacidade lingüística plena quanto à aquisição de estruturas subordinadas.

\section{Quadro teórico}

Uma vez que pretendemos analisar lingüisticamente a produção escrita de P.H., é necessário esclarecermos qual a concepção de texto que nos norteará nesta análise. Sabemos que dificilmente um conceito de texto será capaz de abranger todos os elementos que efetivamente fazem de uma produção escrita um texto, mas parece-nos razoável, dada a natureza do que será enfatizado em nossa análise, que tomemos como referência de texto os estudos de Halliday e Hasan (1976), outros trabalhos decorrentes como os de Kock (1991-1996) e Geraldi (1991) que apontam como relevante o papel do outro para a existência de um texto.

Esses autores concebem o texto como um todo significativo. Na textura desse todo é necessário que mecanismos coesivos estabeleçam conexão entre as suas partes. Dessa forma, o texto não é uma listagem de frases que não se interrelacionam. Por outro lado, admitimos que somente os mecanismos de coesão não garantem a unidade significativa, pois é possível a existência de textos coesos, porém incoerentes, e de outros, sem recursos de coesão explícitos, mas coerentes. De qualquer forma, a noção de coesão, coerência e textura é fundamental no reconhecimento de um texto. É procurando não perder de vista a noção de texto como um todo significativo que olharemos para a produção escrita de P.H.

Também será tomado como ponto de referência o estudo de Perrone (1992) sobre as narrativas e as considerações sobre aquisição de relativas feitas por Gregolin-Guindaste (1996-1997). 


\title{
As produções de $\mathbf{P . H}$.
}

\author{
A narrativa de P.H.
}

O primeiro texto de P.H. a que tivemos acesso foi produzido após a pesquisadora ${ }^{3}$ ter lido para ele a história Chapeuzinho Vermelho (que ele dissera já conhecer). A proposta era que ele a recontasse por escrito.

Vejamos o texto:

O lobo mal veio atingir a vovó por que estava com fome

Ele acreditou que o chapeuzinho vermelho que ele vai comer o chapeuzinho vermelho.

Curitiba, 18 de julho de 1997.

Este texto evidencia que P.H., apesar dos seus 12 anos e de cursar a $4 .^{\text {. }}$ série, não tem domínio dos elementos da narrativa. Embora ele tenha incluído, em sua versão da história, três personagens importantes, não conseguiu apreender as idéias principais de cada etapa da história para que pudesse recontá-la resumidamente. P.H. ignorou todos os aspectos referentes à caracterização das personagens, à localização espacial da situação, ao desenvolvimento da ação e, principalmente, ao desfecho (ele não incluiu o caçador na sua tentativa de reprodução da história). No primeiro parágrafo, vemos que ele ateve-se unicamente à causa de o lobo "atingir" a vovó. É interessante notar como a estrutura desse parágrafo constitui algo que poderia ser uma resposta a uma pergunta canônica da modalidade escolar de interpretação de textos:

Por que $X$ fez $Y$ ?

$X$ (o lobo) fez $Y$ (atingiu a vovó) porque $Z$ (estava com fome).

No segundo parágrafo, P.H. não consegue bom desempenho com as orações subordinadas. Em Ele acreditou que o chapeuzinho vermelho que ele vai comer o chapeuzinho vermelho não temos uma estrutura bem formada. A dificuldade sintática evidenciada nesse tipo de período complexo compromete a clareza de seu texto.

Uma hipótese é que ele teve dificuldade com o segundo que do período, que poderia ser um pronome relativo, se ele desse continuidade adequada ao

3 Profissional do projeto de extensão "Diagnóstico e acompanhamento longitudinal de casos-problemas de alfabetização", da Universidade Federal do Paraná, que atende P.H. na Escola Estadual Aline Picheth, em Curitiba. 
enunciado. Entretanto, quando solicitado a ler o que escrevera, parou nesse que e falou sem ler: Ele acreditou que ia comer o chapeuzinho vermelho.

Apesar da má formação do período, tal problema não se deve ao uso da conjunção integrante, o que confirma evidências anteriores constatadas em estudos de agramatismo (Gregolin-Guindaste, 1996): o sujeito pode ter dificuldades com o "que" relativo e não com o "que "integrante.

Quanto ao domínio dos requisitos para a competência para a narrativa, a refacção oral do texto feita por P.H. durante a experimentação evidenciou seu conhecimento a respeito de tempos verbais usados na narrativa, uma vez que ele retirou a forma vai comer, discursivamente um futuro, tempo não adequado a narrativas, e substituiu-a por ia comer.

$E ́$ interessante notar que, apesar de ele ter pulado uma linha entre um parágrafo e outro, o que aparentemente transforma seu texto em duas sentenças desvinculadas, P.H. estabelece uma relação anafórica remetendo o pronome ele da segunda frase ao lobo mal da primeira, o que significa algum conhecimento da utilização de recursos coesivos.

Em resumo, P.H. reduziu a história Chapeuzinho Vermelho a duas frases (uma referente à vovó e outra a Chapeuzinho Vermelho), que possivelmente constituiriam respostas (provavelmente com algum grau de inadequação) a um suposto questionário sobre o texto, sem levar em conta o todo da narrativa.

Uma análise que se voltasse mais para as questões discursivas da linguagem certamente constataria que P.H. apresenta grandes dificuldades na interação verbal, uma vez que ele ignora o outro nesse processo. Não houve nele a preocupação em apresentar ao possível leitor de sua produção textual o contexto dos fatos que ele pretendeu narrar. Não foi explicitado que relação havia entre as personagens que ele citou, onde estavam, o que faziam ou que fim tiveram. Não houve orientação, complicação, desfecho e nem coda. P.H. não visualiza o que o leitor de seu texto precisa para entender o que para ele (P.H.) já está resolvido.

\section{O texto e as condições de produção}

$\mathrm{O}$ texto abaixo também foi produzido na presença da pesquisadora. A proposta era a produção de um texto, apresentando-se a uma pessoa que iria conhecê-lo.

Curitiba, 25 de junho de 1997

Oi eu sou Paulo 
É um prazer em conhecer

Eu gosto de fazer lição, assistir televisão, sair com a minha mãe, copiar as lições

de sala de aula, escutar musicas, assistir filmes e novelas.

Eu tenho 12 anos

Eu estou na $4^{a} \mathrm{c}$ da escola estadual Aline Picheth.

Eu tenho um irmão se chamado Vitor.

Ele tem 9 anos e está na $2^{\mathrm{a}} \mathrm{B}$ também nessa escola.

O meu pai se chama Waldemar e ele tem 43 anos.

A minha mãe se chama Maria Lucia e ela tem 39 anos.

Eu estudo de manha

O meu irmão estuda de tarde

O meu pai é ministro responsavel da Igreja Messianica.

A minha mãe professora de Ikebana da Academia Sanguetsu tambem nessa igreja

Eu nasci no dia 1 de junho de 1984.

O meu irmão nasceu no dia 2 de abril de 1988

O meu pai nasceu no ${ }^{4}$

As duas primeiras frases do texto de P.H. são o que podemos chamar de frases feitas, mas isso não é incomum neste tipo de situação em que se simula o início de um discurso de característica bastante convencional (as apresentações, as saudações etc). $O$ fato de ter sido deixado vazio o lugar do objeto do verbo conhecer pode ser considerado como uma marca de oralidade no texto escrito, mas esse não é problema relevante, uma vez que esse vazio é uma tendência na fala, inclusive de pessoas cultas. Realmente singulares sāo as demais características do texto de $\mathrm{P} . \mathrm{H}$.

É interessante notar que, a exemplo do primeiro texto analisado, ele separa os parágrafos por linhas em branco, fazendo com que sua produção escrita não se apresente, nem visualmente, como um texto coeso, mas sim como frases desvinculadas. Observa-se que, quando ele se refere aos seus gostos (linha 3), usa adequadamente a pontuação, separando por vírgulas as diversas orações que se subordinam a $E u$ gosto de. Entretanto, não repete essa estrutura nos momentos seguintes, e, como que num processo de colagem, escreve várias frases, com estruturas que se repetem por diversas vezes (sem constituir recurso estilístico, evidentemente). $\mathrm{O}$ marcante nesse texto é que, embora seu tema (P.H. e sua família) fosse bastante propício à sua revelação enquanto sujeito, isso não acontece. Seu texto é muito pobre em adjetivos, o que causa estranheza, se

4 O processo foi interrompido, pois o horário de que eles dispunham para esse trabalho já se esgotara há algum tempo. 
considerarmos todas as caracterizações que ele poderia fazer de si mesmo e de seus familiares. Esses problemas atribuem ao texto um caráter bastante artificial, característico de processos mecanicistas de aprendizado de escrita.

P.H. não sabe coordenar informações unindo nome, idade e data de aniversário, mas consegue usar a partícula "também", o que pode ser constatado no texto.

Apesar da artificialidade presente nesse segundo texto, a exemplo do primeiro, aqui novamente se esboçam alguns indícios da coesão textual, via retomadas anafóricas. Ele é uma retomada de Vitor; nessa escola retoma escola estadual Aline Picheth (linha 8); ele remete a o meu pai (linha 9); ela remete a a minha mãe (linha 10); e nessa igreja retoma Igreja Messiânica.

Em Ele tem 9 anos e está na $2^{a}$ B também nessa escola, P.H. se vale de uma elipse de ele, mas não repete esse tipo de recurso em outros dois casos em que poderia fazê-lo: $O$ meu pai se chama Waldemar e ele tem 43 anos e $A$ minha mãe se chama Maria Lucia e ela tem 39 anos. No caso anterior, se ele não se valesse da elipse, teria que repetir o ele: Ele tem nove anos e ele está na $2^{a} B$ também nessa escola.

Já o caso a seguir, à primeira vista, poderia parecer uma elipse, mas as evidências apontam para uma outra explicação. Observemos:

O meu pai é ministro responsavel da Igreja Messianica A minha mãe professora de Ikebana da Academia Sanguetsu tambem nessa igreja

Na segunda frase, provavelmente há uma omissão do verbo ser.

Um problema também interessante acontece em Eu tenho um irmão se chamado Vitor. Possivelmente a presença de se ocorre devido à possibilidade de ter sido cristalizada na memória a forma de uma construção bastante usada com o verbo chamar: chamar-se. Ele poderia ter escrito Eu tenho um irmão que se chama Vitor, mas a sua dificuldade com relativas e sua tendência para colagem de frases feitas podem ter ocasionado a produção de uma sentença sintaticamente desestruturada.

Quanto aos aspectos convencionais da escrita, o texto apresenta alguns poucos problemas, se for considerado o padrão de escrita convencional: há falta de alguns diacríticos e de pontuação. Quanto à regência de assistir, P.H. vale-se do que é comum na fala, sendo que esse não atendimento à regência padrão já constitui uma forma em variação no português do Brasil. Vale ressaltar que, 
exceto a falta dos diacríticos, não se verificou nenhum outro problema na grafia das palavras.

Esse bom desempenho de P.H. na ortografia, em oposição aos problemas de textura do texto e de sintaxe, constitui um típico exemplo de que o aprendizado do código escrito não garante a apropriação da escrita enquanto atividade cultural complexa. Nesse sentido, vale lembrar Vygotsky, quando diz que se deve ensinar às crianças a linguagem escrita e não apenas a escrita de letras. (1984, p. 134)

\section{A falta de unidade temática}

O texto a seguir foi produzido após uma conversa entre P.H. e a pesquisadora a respeito de cidades que eles conheciam. A proposta era escrever sobre uma cidade que ele considerasse importante ou de que mais gostasse. A pesquisadora também escreveria um texto com um desses temas. Era uma forma de garantir o leitor, pois afinal um texto só é texto se for dado a público, conforme aponta Geraldi (1991).

Vejamos como P.H. escreveu seu texto:

Eu gosto mais da

Uma cidade legal

Eu nasci em São Paulo e conheço as cidade de Sertãozinho, Curitiba, Florianopolis,

Porto alegre, Londrina, etc.

Eu gosto mais de São Paulo por que eu gosto de ir no Macdonald's, no Carrefour, no Eldorado e no Center Norte.

Em Porto Alegre eu gosto de ir no Praia de Belas Shoping Center e no Aeroporto

Internacional Salgado filho, onde eu posso ver os vôos domesticos e internacionais.

O que eu acho mais emocionante é o que eu reprovei 2 vezes e eu não quero reprovar denovo.

O problema deste texto é a falta de unidade temática. Além do último parágrafo (sobre reprovação) ser um exemplo claro de fuga ao tema, o parágrafo referente a Porto Alegre também se distancia da proposta, que era escrever sobre uma cidade. 
Ele realiza algumas operações de refacção não só para resolver problemas ortográficos (Eudorado/Eldorado; Carefour/Carrefour), mas também substituindo palavras por ter mudado de idéia a respeito do que escrever (conheço/nasci). Isso evidencia algum tipo de reflexão sobre o conteúdo de seu texto.

Segundo relato da pesquisadora a respeito da produção desse texto, P.H. enfrentou um problema interessante na hora de dar o título a ele. Escreveu Uma cidade legal, mas disse a ela que estava em dúvida, pois achava que tinha que ser Umas cidades legais, porque escrevera sobre duas cidades. Por fim, falou que ia deixar no singular mesmo, pois gostava mais de São Paulo. Essa dúvida de P.H. demonstrou que, por alguns momentos, sua atenção se voltou para uma questão pertinente à coerência textual. Se ele escrevera sobre São Paulo e Porto Alegre com relevância positiva equivalente, o título não poderia ser Uma cidade legal. Entretanto, P.H. não seguiu esse raciocínio até o final. Para ele, o fato de gostar mais de uma cidade só (São Paulo) foi a justificativa para deixar o que escrevera no singular.

Em relação ao último parágrafo, consideramos relevante registrar que antes de P.H. escrevê-lo, a pesquisadora perguntou-lhe se, no aeroporto, ele achava mais emocionante ver as decolagens ou as aterrissagens, ao que ele respondeu que as decolagens eram mais emocionantes. Após esse diálogo é que ele começou a escrever o parágrafo em questão. Observamos que certamente o conteúdo semântico polissêmico de mais emocionante (linha 9) remeteu P.H. a uma outra situação de sua história. Naquele momento, o mais emocionante para ele deixou de ser a decolagem do avião, que lhe trazia emoção relacionada à alegria, para que ocupasse espaço a questão da reprovação, que certamente se relaciona à tristeza e humilhação. Ele passou de um script a outro, sem refletir sobre a inadequação do segundo em relação à proposta do seu texto. Faltou-lhe o conceito de tex to como sendo um todo articulado e coerente, por isso a escolha lexical foi inadequada.

\section{Considerações finais}

Os textos de P.H. atestam que sua relação com a língua escrita é acentuadamente behaviorista. Certamente, em seu ingresso no mundo da escrita, não estiveram presentes fatores importantes como, por exemplo, a função da escrita e sua constitutividade na interação social. Além disso, possivelmente, por apresentar problemas de ordem emocional, que interferem na qualidade de seu relacionamento com as pessoas, ele teve seu desempenho lingüístico prejudi- 
cado, uma vez que, numa perspectiva interacionista, a linguagem é tecida nas relações sociais.

Apesar de se valer de alguns recursos coesivos, de um modo geral não consegue bom amarramento das partes de seu texto, ora por problemas de coesão mesmo, com repetições desnecessárias, ora por não respeitar a unidade temática, além do desconhecimento da estrutura da narrativa. A incapacidade para encaixar sentenças, um problema cognitivo de ordem sintática, detectado em experimentações que têm sido feitas com P.H. durante o acompanhamento e relatado em Gregolin-Guindaste (1997) pode ser também uma das causas originárias dos problemas textuais. Isso faz com que sua produção escrita se pareça com frases feitas e artificiais, características de uma alfabetização tradicional, que trata a linguagem como uma habilidade motora a ser adquirida com treinamento.

Convém ressaltar que P.H. está na 4. ${ }^{\text {a }}$ série do ensino fundamental, o que significa que ele vem sendo aprovado, apesar de não produzir textos. Significa, ainda, que a escola que o aprova tendo em vista seu desempenho ortográfico não é capaz de ensiná-lo, de fato, a escrever.

Os problemas sintáticos detectados na linguagem de P.H., referentes ao não-domínio de relativas, podem ser responsáveis pelo não-encadeamento de orações, o que prejudica a tessitura do texto, mas não impede o uso de elementos de coesão textual.

Não queremos atribuir valor negativo ao bom desempenho de P.H. em relação à convenção da escrita e ao uso de alguns elementos coesivos. Queremos, sim, ressaltar que o domínio da ortografia não garante o domínio da língua em situações concretas de uso. O problema da escrita de P.H. é que esta se desenvolveu unilateralmente. De maneira geral, ele apenas repete as estruturas aprendidas (decoradas) nos primeiros anos escolares e anula-se enquanto sujeito. Não se pode dizer que saiba valer-se da escrita nas situações em que ela é exigida. Não conseguiu, ainda, livrar-se das amarras do processo de alfabetização limitado pelo qual passou. Isto, aliado à incapacidade cognitiva de encaixar sentenças subordinadas, tem como resultado uma escrita escolar que não constitui texto.

Em seu último texto, intitulado Uma cidade legal, P.H. faz uma tentativa. É paradoxal, mas exatamente no parágrafo que foge completamente ao tema, ao escrever sobre o que lhe causa emoção, ele consegue estabelecer um vínculo entre a sua produção escrita e a sua história. Se ele quiser continuar a escrever sobre as coisas que realmente lhe importam (e se suas condições emocionais permitirem), certamente vai modificar sua relação com a escrita, para poder apresentar suas marcas de individualidade. 


\section{REFERÊNCIAS BIBLIOGRÁFICAS}

GERALDI, J. W. Portos de passagem. Campinas: Martins Fontes, 1991.

GREGOLIN-GUINDASTE, R. M. A linguagem de aprendizes: singularidade de casos. Revista Letras, n. 48, 1997. No prelo.

A produção de textos nos primeiros anos de escolaridade. Jornal da Alfabetizadora, Porto Alegre, n. 11, 1990.

Agramatismo: um estudo de caso em português. Campinas, 1996. Tese de Doutorado - Universidade Estadual de Campinas.

HALLIDAY, M. A. K.; HASAN, R. Coesion in English. Londres: Longman Group, 1976.

KOCH, I. A coesão textual. São Paulo: Contexto, 1991.

; TRAVAGLIA, L. C. A coerência textual. 7. ed. São Paulo: Contexto, 1990.

PERRONE, M. C. Desenvolvimento do discurso narrativo. São Paulo: Martins Fontes, 1992.

VIGOTSKY, L. S. A formação social da mente. São Paulo: Martins Fontes, 1984. 